\title{
MULTICULTURALISM IN DISTANCE ART EDUCATION
}

(Paper submitted to Marilyn Zurmuehlen Working Papers in Art Education)

\author{
Alice Lai \\ Department of Art Education \\ The Ohio State University \\ Lai.78@osu.edu
}




\section{MULTICULTURALISM IN DISTANCE ART EDUCATION}

\section{Introduction}

The rapidly increasing number of distance education courses in the United States is steadily changing the way people teach and learn. The task of implementing distance education into the field of art education is much more, however, than the simple insertion of fashionable technological tools into the learning environment. It demands the careful reconsideration of curriculum concepts, of multicultural art teaching, of the diversity of learners' cultural backgrounds, and of the course objectives.

In this study I develop a descriptive and analytical account of multiculturalism in university-level distance art education, based on data collected with educational ethnographic research methods including participant observation, interviews, and surveys. I begin with a review of multicultural education and cultural diversity in distance art education. Then, I introduce the online course studied (AE367.D01: Ethnic Arts) by discussing the course objectives, students' backgrounds, and the online technology-mediated environment. Using samples of students' written work as examples, I analyze how distance education can facilitate multicultural learning of ethnic arts. Finally, I conclude by reviewing pedagogical considerations that are necessary in the implementation of multicultural distance art education. 


\section{Multiculturalism, Cultural Diversity, and Distance Education}

Ever since the civil rights movement of the 1960s, the United States has been increasingly recognized as a multicultural society. Conflicts among diverse ethnic, racial, gender, class, and political groups have caused educators, sociologists, politicians, and thinkers in many other disciplines and professions to rethink the socio-cultural structure of American society along such lines. Gollnick and Chinn (1998), for example, assert that the United States consists of the dominant cultural group as well as numerous subsocieties or subcultures, providing such concepts as macroculture and microculture to describe this complexity:

Groups in the United States have been called subsocieties or subcultures by sociologists and anthropologists because they exist within the context of a larger society and share political and social institutions, as well as some traits and values of the macroculture. These cultural groups are also called microcultures to indicate that they have distinctive cultural patterns while sharing some cultural patterns with all members of the U.S. macroculture. (p.13)

Recognizing and responding to such complexity, they have promoted multicultural approaches to education:

Multicultural education is the educational strategy in which students' cultural backgrounds are used to develop effective classroom instruction and school environments. It is designed to support and extend the concepts of culture, differences, equality, and democracy in the formal school setting. (p. 3).

In their view, multicultural education can actually empower students by including students' cultural backgrounds into the learning process, and by providing equal schooling opportunities for diverse student populations. Multicultural education is 
responsive to the current socio-cultural paradigm and is able to fulfill the needs of diverse students, thereby improving the quality of education.

Multicultural education is a means for integrating cultural diversity into the total learning process (Banks, 1997; Gollnick \& Chinn, 1998). One critical task, therefore, is to design and implement multicultural curricula in such a way as to incorporate issues related to students' diverse microcultural background (especially regarding race, gender, ethnicity, and class) into day to day teaching practices. In addition, teachers need to become aware of the particular points of view from which they are teaching so that they not teach only one group's perspective and values. Any one perspective should refer to its interrelationship with other perspectives as well, lest students view their own (micro)cultures as totally distinct and separate from all others. This may result in students feeling that they are observing cultural activities as complete outsiders, causing them to feel too intimidated to make connections to such activities, and making it impossible to break down the boundaries between members of different microcultures. An awareness of multiple points of view and their interrelationships enables students to achieve multicultural learning based on the larger cultural context.

Multicultural education can be implemented not only in the conventional classroom, but in distance education as well. A number of researchers have taken distant learners' diverse cultural and educational backgrounds into consideration as one way to improve distance education (Stankiewicz \& Garber, 2000; Krug, 1997-8, 1999; Starkey, 1998; Freedman \& Liu, 1996; DeVillar \& Faltis, 1991). These researchers believe that to fully take advantage of distance education, teachers need 
much more than just training in operating new machines and technical support. Stankiewicz and Garber (2000) claim that, "distant faculty must learn to teach effectively without cues from body language, and they also need to understand students' lifestyles, cultures, and experiential worlds" (p. 35). Furthermore, Krug (1999) points out that teachers, in addition to staying current with the rapidly increasing technological challenges, need to learn new pedagogical methods and facilitate inquiry with a greater diversity of learners in the classroom.

Several researchers indicate that distance education has enhanced cultural awareness (Starkey, 1998; Freedman \& Liu, 1996; DeVillar \& Faltis, 1991). Such research is in agreement that through various technological means (e.g. the Internet, e-mail, multimedia), students are able to explore locally and internationally different artifacts, languages, places, and people. Therefore, knowledge about people, artifacts, and the life of other cultural groups can be brought to light in larger cultural context. Students of art education will be able to study art through multiple resources and gain insight into different values, beliefs, and practices of art.

Moreover, Schofield (1995) and Lai (1996) assert that distance education can create a positive multicultural learning environment. Because of the lack of certain social cues in an on-line environment, distant learners will most likely pay more attention to the content of messages. This can shift learners' attention away from personal biases toward certain cultural (or racial, or gender) groups, and toward the topic discussed. Thus, these researchers believe that distance education can provide students with a non-threatening learning atmosphere. It helps to create a comfortable environment for students to ask questions and interact with each other. It can further 
help to foster an environment of equal learning opportunity where everyone can have a voice, and voices can be heard.

On the other hand, Bromely (1998) points out a problematic assumption associated with multiculturalism in a technology-mediated learning environment. The continually increasing promotion of computing technology in the American educational system runs the risk of encouraging teachers and students to think of such technology as a neutral tool assumed to benefit all students equally. (For example, students who are disabled or who live in remote areas are able to achieve their learning goals by taking advantage of teleconferences or online courses.) However, an examination of the U.S. economic system, accessibility to computers in different communities, and students' performance in technology-enhanced learning environments reveals unequal distributions along the lines of gender, race, class, religion, and ethnicity. Fabos and Young (1999) call attention to another problematic aspect of multicultural distance education, namely, online learners fashioning themselves as electronic tourists from the safety of their computer screen and a dominant American perspective. When distant learners share diverse cultural experiences, it is possible that American students' understanding of others may simply be based on dominant American and Western perspectives, consequently privileging notions of Western imperialism.

What is clear from these analyses is that distance education does possess the potential to facilitate a multicultural learning environment, but that teachers will need to pay close attention to certain pedagogical considerations. In order to improve multicultural practice in distance education, they need to be aware of their own 
conceptions and the conceptions of their students regarding computer technology and cultural diversity.

The Online Course Studied - AE367.D01: Ethnic Arts

The distance education course I studied is Art Education 367.D01: Ethnic Arts: A Means of Intercultural Communication (AE361.D01: Ethnic Arts), one of the undergraduate General Education Curriculum (GEC) courses offered in the Department of Art Education at the Ohio State University. This course was designed to fulfill three GEC requirements in arts and humanities, cultural/social diversity, and second level writing. AE367.D01: Ethnic Arts examines a wide range of artists, artworks, and art worlds from diverse ethnic and cultural groups in North America. These groups include, but are not limited to, African American, Asian American, Chicano/a, Korean, Chinese, Japanese, Indian American [India], Mexican American, European American, and Native American. Examples of the wide variety of ethnic arts studied in the course are costumes, baskets, musical instruments, body adornments, quilts, festivals, ethnic dances, and foodways. The course emphasizes how diverse ethnic and cultural groups conceive of art, and how they interpret its values, meanings, and functions. The various teaching and learning materials introduce theoretical and philosophical discussions about art and its role in human society. By reading case studies of artists, artworks, and art worlds at the local, state, national and international level in North America, students are encouraged to examine personal and social biases and stereotypes revealed by works of ethnic arts.

The online course I studied was composed of a diverse student body. In the Winter 2001 quarter, twenty students enrolled initially, and twelve students 
completed the course. There was one Asian American student, one Taiwanese student (the only one for whom English was a second language), one Jamaican American student (a full-time working mother of two children), and nine white traditional university students. There were three art- and art education-related majors and nine non-art-related majors. There were four male students and eight female students. Most of students lived close to the campus and were taking other university courses (online and on campus) at the same time. Several students were able to travel while taking the online course. The Taiwanese student whose major was music was able to travel to different states for auditions. A student majoring in political science traveled with his political party during the campaigns. Several students increased their number of visits to their parents' homes while taking this distance education course. During the course of the study, students were encouraged to share with each other their diverse educational, cultural, and lived experiences. They frequently discussed family stories, lifestyles, and out-of-town traveling experiences throughout the course.

The creators of the course web-site (led by Don Krug) for AE367.D01: Ethnic Arts, digitized course readings, lecture notes, visuals, films, and audiotapes. These online materials allowed students to browse, read, or print out from their computer screen and study them on their own, when and where they wanted. The course web-site incorporated such interactive multimedia as the Internet, video streaming, audio, animation, and hypertext. WebCt was used to manage the course web-site, teaching materials, and students' portfolio. WebCt also provided such communication tools as discussion forums, chat rooms, and student presentation 
pages. A listserv was set up for facilitating a one-to-all e-mail correspondence. Email correspondence, discussion forums, and chat rooms were implemented for the purpose of facilitating communication, social interaction, and writing. Online participants used these tools to contact each other to express and argue about their ideas regarding ethnic arts, to solve problems, to complete assignments, and for the instructor to evaluate learning outcomes.

\section{The Facilitation of Multicultural Learning by Distance Education Technology}

The implementation of various communication tools plays a crucial role in facilitating multicultural learning of ethnic arts. Using e-mail correspondence, discussion forums, and chat rooms, distant learners are able to express, exchange, and argue about their ideas regarding ethnic arts in a variety of flexible ways.

Because each of these communication technologies has its own characteristics, each is implemented in its own particular way. Such variety allows students to experience various learning dynamics in multiple settings. The following chart indicates how each of these communication technologies can be of importance in facilitating multicultural curriculum concepts.

\begin{tabular}{|l|l|l|}
\hline Tools & Characteristics & Multicultural curriculum concepts \\
\hline E-mail & Person-to-person & To express and share different \\
viewpoints concerning arts \\
To tell personal stories in relation to \\
ethnic arts \\
To enhance social interaction and \\
online social skills \\
To build interpersonal relationships \\
To help each other clarify ideas \\
To experience cultural diversity \\
through different kinds of textual \\
& Interactive communication & performance \\
& & \\
& & \\
& & \\
& & \\
& & \\
\end{tabular}




\begin{tabular}{|l|l|l|}
\hline Discussion Forums & $\begin{array}{l}\text { Individual } \\
\text { Person-to-class } \\
\text { Team-to-class } \\
\text { Asynchronous } \\
\text { Formal writing, posted weekly }\end{array}$ & $\begin{array}{l}\text { To present student's portfolio } \\
\text { including writing \& visuals } \\
\text { To allow feedback to the portfolio } \\
\text { To foster writing skills } \\
\text { To perform the understanding of } \\
\text { weekly learning materials } \\
\text { To read interpretation and analysis of } \\
\text { ethnic arts from various viewpoints }\end{array}$ \\
\hline Chat Rooms & $\begin{array}{l}\text { Person-to-person } \\
\text { Person-to-team } \\
\text { Synchronous } \\
\text { Interactive } \\
\text { Informal conversations } \\
\text { Quick writing } \\
\text { Almost no editing } \\
\text { Allow immediate response } \\
\text { Small group activity }\end{array}$ & $\begin{array}{l}\text { To discuss ideas at the same time } \\
\text { To conduct visual critiques } \\
\text { To exchange visual information } \\
\text { To foster small group interaction } \\
\text { To provide on-site answers or help } \\
\text { To share personal opinions } \\
\text { immediately }\end{array}$ \\
\hline
\end{tabular}

All of these communication tools are text-based, and open to all the students enrolled in the course. Thus, the students' diverse opinions, beliefs, ideas, and arguments associated with ethnic arts, as well as their individual writing styles and manners were all open for discussion. This enabled students to become aware of each other's (and their own) ideas about ethnic arts. During the course of study, some students were asked by others to clarify their personal cultural beliefs through the email correspondence. Some students challenged each other's beliefs regarding certain issues. When addressing ideas using E-mail correspondence and Chat Rooms, students were highly self-reflexive, often writing about their own personal opinions and lived experiences, provoking them to discuss the issue of cultural diversity as well. On the other hand, when posting weekly writing assignments, students were asked to logically and thoughtfully use references (i.e. course readings and other members' arguments) to support their position. Such formal writing practice seemed 
to foster students' ability to understand particular issues, as well as to compare and contrast arguments about ethnic arts in a larger context.

In this online course, the interactive discussions indeed helped students realize and sometimes experience personal biases regarding certain social and cultural groups of which they are a part. Students were able to discuss various issues in relation to their current educational, cultural, and lived experiences. Consider, for example, one of the weekly study units entitled "Body Adornment." During that week, Mary ${ }^{1}$ volunteered to lead a weekly listserv discussion. After reading several assigned case studies about different ethnic groups' body adornment, she posted several questions to the class through e-mail correspondence. She encouraged all participants to write interactively to discuss the functions of socioeconomic status, gender, race, and age in relationship to various ethnic groups' body adornment and their methods of production. One of her requests evoked a variety of responses, and the discussion proceeded as follows: ${ }^{2}$

Mary: Discuss your personal experience of social injustice associated with ethnic arts. (Feb. 5, 2001)

Anne: For so long I wanted [Tattoo] on my ankle, but now I've decided to change my mind. I wouldn't want a tattoo to effect my chances of getting a job. If I found a job I wanted in which I would have to wear a skirt, I would be afraid that my boss would think it was unprofessional. (Feb. 6, 2001)

Ray: why would you HAVE to wear a skirt? and once you had the job i think that your work performance wouyld far out weigh a tattoo. (Feb. 7. 2001)

Mel: I think that if I told my grandmother that my boyfriend had a tatoo (he doesn't by the way)...I don't necessarily think that she would flip out...however, a tatoo really isn't her choice of attractive...but she'd accept it. I think that your opinion really has a lot to do with the way that you were brought up For instance, if you were brought up in the slums of a big city...I think that it's more likely that you will accept it or have a tatoo than someone who was brought up in Idaho, or Iowa. Sorry if anyone's from there...I don't mean to offend anyone. (Feb. 7, 2001)

Anne: Many of you think that the stereotypes of tattoos will eventually fade away. Sometimes we think our parents and grandparents are wrong for judging people with tattoos. But when you guys become grandparents and parents don't you think you may think the same thing? I personally couldn't imagine my grandma or myself as a grandma with a tattoo. What do you guys think? (Feb. 8, 2001) 
Mary: I agree with Anne. I think it is also less acceptable for woman to have tatoos, than man. I have heard people that I looked up to, say that guys with tatoos are "stupid", but women with tatoos are "trashy". But if your affraid of people stereotyping you, you can always cover tatoos. (Feb. 7, 2001)

Ben: I agree with Cindy when she says that many of the negative attitudes of tattooing will fade as the older generation moves. This process will probably take a long time though, because each consecutive generation will be influenced by the previous one, and there will still be some opposition to tattooing. (Feb. 8, 2001)

Julie: I think that the reason there are (mis)conceptions about women having tattoos and being trashy, is because many of the women we see with tattoos are the ones who flaunt them, as well as other things. They do things to impress men and women. This can also include their style of dress. We will rarely see women who have tattoos for a more personal basis, and so therefore we assume that the trashy ones speak for the rest of the women. (Feb. 11, 2001)

Ray: who are these people you speak of the... flaunty ones. I have had my tounge pierced for well over five years now and i remember when i first got it $i$ showed it to people, friends \&amp; family mostly. Befor that i had my lip pierced.\&nbsp;I guess that it was around 1995 and at that point the only people you saw on tv with anything pierced, other than the navel, were dirty punk rockers with safety pins, or tribes people on discovery channel. Why were you so embarresed, to your sweet old grandmother and to the 7 year olds both? (Feb. 12, 2001)

Mel: sometimes I feel like people do [tattoo] just for the attention...I mean...do biker dudes really have to ride their bikes without shirts on!? Not the kind of thing I like to see on a daily basis...Unfortunately because the majority of biker people have tatoos and usually wear cut off leather...tatoos and flaunting them have become a characteristic of them... (Feb. 12, 2001)

Ray: quite amusing... but in the bikers defense, i would rather see some nasty "biker dude" blazin' ink than some girl wearing acid wash, denim pants with an extremely high waist, with matching puffy socks-sweat shirt-and ear rings...feel free to replace anything.... for the look! iiiiiicccckkkkk!!!!! (Feb. 12, 2001)

Julie: Besides a couple of my friends having tattoos and not being showy, I have yet to see a majority that doesn't flaunt it. It's just an opinion of what I see. I even said that my statement was due to my surroundings and opinion. :) (Feb. 12, 2001)

Ray: i'm not disagreeing with you, entirely i feel that a lot of people are showy and a large portion of those people are in it for the attention it is unfortunate for those who have done it for other reasons and now have to live with the stigma. (Feb. 12, 2001; E-mail correspondents of AE367.D01: Ethnic Arts, February 5-12, personal communication, 2001)

In this case, one can readily sense the intensive and interactive multicultural learning dynamic operating in the online course studied. Using e-mail correspondence, students wrote arguments self-reflexively based on their understandings of gender roles, family lifestyles, mass media, class differences, and so forth. Cross-cultural comparisons were mentally processed when they read each 
other's responses and thought about, for example, why Ray, Mel, and Julie had strong yet different reactions to the negative attitude concerning tattoos. It seems obvious that students, although from similar cultural and educational backgrounds, may hold different beliefs and attitudes toward body adornment due to differences in family structure, schooling experience, and the influence of the mass media. As discussed above, one of the aspects of multicultural education is viewing students' cultural backgrounds as essential to the learning process. This particular learning unit on body adornment achieved such a goal through a listserv which allowed students to express their cultural backgrounds, challenge each others' conceptions, and deal with a wide variety of issues like gender, education, age, and class.

Next, consider students' written work from the discussion forum in this unit on body adornment. At the end of the week's listserv discussion, each student summarized the most stimulating idea he/she learned from the assigned readings, visual materials, and listserv discussion. Since the discussion forum is a formal writing area, it requires that students use outside resources, other than personal experience, to support their arguments. It also encourages students to express their thoughts in an organized, logical, and precise manner. For example, Cindy wrote in part of her summary:

According to [the author] Stuhr's argument [...] piercing can an example of a "transitional" change. This form of body modification has been around since the Indian tribal days. It has gone from ear piercing to tongue, belly button, nose, eyebrows and even one's private parts. In society today, piercing is not as much an isolated issue as it was back then. As I've learned from this week's discussion, I believe that more and more people are having their body parts pierced. Although not everyone agrees on the idea of having tattoo, we all agree today's people understand what and why they want on their body [...]. (Cindy, personal communication, February 10, 2001) 
As we see in Cindy's example, students often included information on body adornments from various sources, and often tied their interpretation of art to social and cultural issues.

Online communication through reading and writing is an important educational and social activity. Janassen, Peck, and Wilson (1999) state that although we normally think of knowledge construction as an individual process, it can become a social process when students participate actively in online communication. Reading and writing intensively and interactively allows students to experience cultural diversity. Though it may increase tensions between gender and age groups, when participants work together and discuss what they are doing and why, they can develop and refine knowledge of and sensitivity to the topics discussed. In the writing process, participants become highly aware of their arguments. Their words, manner, style, and other textual elements often reveal their personality, as well as their cultural, historical, and educational backgrounds. In a sense, distance education which uses a variety of communication tools in different ways can facilitate students' multicultural learning experiences in ethnic arts.

\section{Conclusions}

I have indicated several ways in which multicultural learning was fostered in this online course on ethnic arts. The curriculum concepts, the inclusion of students' diverse cultural and educational background into the learning units, and the use of three communication tools have helped to achieve the goals of multicultural art education. 
In a multicultural art curriculum, teachers do not simply introduce mainstream art and aesthetics from the Western canon. Rather, they introduce arts and artists from diverse social and cultural groups to facilitate students' knowledge and experiences of various artworlds. Learning arts from a wider perspective helps students to understand their own worldviews as well as those of others. It can also be a way of encouraging students to investigate unequal power structures and contemporary social and educational conditions. As the above examples indicate, students are able to analyze various class, gender, and age issues related to ethnic arts.

The inclusion of students' diverse backgrounds into the learning units is one of the useful strategies in facilitating multicultural approaches to art. However, the teachers should encourage not only self-reflexivity but also cross-cultural comparison and contrast, and socio-cultural critical analysis to study issues and values relating to ethnic arts. Such a strategy avoids the mere exchange of personalopinions and enhances learning from the view of larger multicultural contexts. Sharing personal stories was one of the motivations for the students in this online course to participate in online discussions (Mary \& Cindy, personal communication, April 6\&7, 2001). Subsequently, students were willing to provide each other thoughtful responses, as well. Such feedback allows students to compare and contrast ideas cross-culturally, and, consequently, to analyze art critically, connecting it to their socio-cultural understanding of today's multicultural society.

Connectivity and interactivity are critical to online learning. Students need to be motivated to log on and participate in online discussion as well as to respond to 
others' postings. Therefore, various communication tools should be developed and utilized to facilitate multiple communication dynamics. Distance education technologies should be integrated to foster individual, person-to-person, person-toteam, and team-to-class learning processes. By doing so, students can address their own opinions to different group of people, and their opinions can be heard and responded to. Throughout self-disciplined yet interactive learning activities, students are able to develop online social relations that, in turn, provide further motivation for participation in learning activities. Learning, multicultural learning in particular, should not be an isolated process; students need to connect to others and interact with each other in order to experience cultural diversity in art as well as in human society.

\section{Acknowledgments}

I would like to thank Don Krug of The Ohio State University for all his guidance and criticism regarding the development and implementation of this project on distance art education.

\section{References}

Banks, J.A., \& Banks, C.A.M. (Eds.), (1997). Multicultural education: Issues and perspectives. (3rd Ed.). MA: Allyn \& Bacon.

Bromley, H. (1998). Introduction: Data-driven democracy? Social assessment of educational computing. In H. Bromley \& M.W. Apple (Eds.), Educational computing as a social practice. (pp. 1-25). New York: State University of New York Press.

DeVillar, R.A., \& Faltis, C.J. (1991). Computers and cultural diversity: Restructuring for school success. Albany, NY: SUNY Press.

Fabos, B., \& Young, M.D. (1999). Telecommunication in the classroom: Rhetoric versus reality. Review of Educational Research. 69(3), 217-259. 
Freedman, K., \& Liu, M. (1996). The importance of computer experience, learning processes, and communication patterns in multicultural networking. Educational Technology Research and Development, 44(1), 43-59.

Gollnick, D., \& Chinn, P.C. (1998). Multicultural education in a pluralistic society. (5th Ed). NJ: Prentice Hall, Inc.

Janassen, D.H., Peck, K.L., \&Wilson, B.G. (1999). Learning with technology: A constructivist perspective. New Jersey: Prentice-Hall, Inc.

Krug, D. (1997-8). Electronic learning communities and art education. Arts and Learning Research, 14, 23-45.

Krug, D. (1999, September). ePortfolios and critical inquiry in art education. Paper presented at the meeting of the International Society of Education through Art. World Congress Brisbane, Australia.

Lai, K. (1996). Words have wings: Teaching and learning with computer networks. Dunedin, NA: University of Otago Press.

Schofield, J. W. (1995). Computer and classroom culture. New York: Cambridge University Press.

Stankiewicz, M.A., \& Garber, E. (2000, January). Cyberfaculty: An experience in distance learning. Art Education, 53(1), 33-38.

Starkey, B. (1998). Using computers to connect across cultural divides. In H. Bromley \& M.W. Apple (Eds.), Educational computing as a social practice. (pp. 175-186). New York: State University of New York Press.

\section{Notes}

${ }^{1}$ All student names are given as pseudonyms.

${ }^{2}$ All quotations of students' writings are literal. 